Нагнібеда М. М.

Кухар B. B.

Ткачов P. О.

Радушев О. О.

Ясько С. Г.

Фролов С. А.

\title{
ВИПРОБУВАННЯ НА ПОПЕРЕЧНИЙ ЗГИН ЗАКРИТИХ АРМУЮЧИХ ПРОФІЛІВ ГНУТОГО ТА ГНУТОЗВАРНОГО ВИКОНАННЯ
}

Сталеві холодногнуті профілі є значущими для суднобудування, машинобудування, будівництва каркасних конструкцій та інших галузей. Через поширеність та попит на армуючий профіль стають жорсткими вимоги до геометричних параметрів та міцності такого виду продукції. Найбільш поширеним процесом виготовлення армуючих профілів 3 необхідними геометричними параметрами є гнуття штаби на багатовалкових прокатних станах $[1,2]$. Контролю якості даної продукції приділяється значна увага через високу значимість сфери їх застосування. Тому актуальним залишається розвиток експериментальних досліджень, що дозволяють розкрити переваги та недоліки конструкцій профілів та технологій їх виготовлення.

Експериментальні дослідження та моделювання з урахуванням властивостей матеріалу є відомими, але у роботах не описується в достатній мірі поведінка заготовок складної форми [3-5]. Дослідження для отримання комплексних характеристик міцності і жорсткості проводяться для суцільних, несуцільних та зварних виробів з урахуванням властивостей матеріалу заготовок, проте вони не враховують форми поперечного перерізу виробу [6, 7]. Biдомим принципом, що розвивається і в цих дослідженнях, $є$ отримання експериментальних даних та їх імплементація для удосконалення процесів багатоперехідного гнуття [8].

Метою даної роботи є визначення відмінностей в комплексних експлуатаційних характеристиках жорсткості сталевого армуючого профілю типорозміру № 40*50 (40 мм $\times 50$ мм), виготовленого багатовалковим формуванням сталевої штаби на профілезгинальному стані у профіль напівзамкненого перетину з зазором між кромками не більше 0,5 мм, сформованим вздовж боку, що має розмір 40 мм (профіль ПГ), та профілю, виготовленого багатовалковим формуванням сталевої штаби в профілезгинальному стані в замкнутий контур і наступним зварюванням кромок з формуванням поздовжнього зварювального шва посередині сторони, що має розмір 50 мм (профіль ПГЗ). Порівняння цих видів профілів iз зазором та наявністю зварювального шва надасть змогу виявити відмінності у поведінці виробів однотипного поперечного перерізу та різних товщин, та, відповідно, надати оцінку розходу листового матеріалу, необхідного для виробництва продукції.

Для проведення експериментального дослідження профілі для випробувань (рис. 1 та рис. 2) були попередньо оглянуті і підготовлені для випробувань. Профілі не мали жодних дефектів, видимих неозброєним оком. 3 кожного типу профілю за допомогою ножівки по металу були вирізані по три зразка профілю з довжиною 1000 мм. Для вимірювання товщини використовувався електронний штангенциркуль «Digital caliper A46» (рис. 3), що пройшов метрологічну повірку в установлені терміни. Були проведені вимірювання товщини стінок заготовок та виконана статистична обробка даних за відповідною методикою [9-11].

Проводили 10 замірів товщини стінки заготовки для кожного профілю. Результати статистичної перевірки адекватності опису даних дослідів за критерієм Фішера та перевірки відтворюваності експерименту за критерієм Кохрена наведені в табл. 1 та табл. 2. Встановлено, що профілі виконання ПГ типорозміру №50 × 40 мають середню товщину стінки 1,936 мм, а профілі виконання ПГЗ типорозміру № $50 \times 40$ мають середню товщину стінки 1,843 мм. 
Таблиця 1

Статистична обробка вимірів товщини стінки заготовки з «Профіль армуючий $50 \times 40$ мм» виконання ПГ

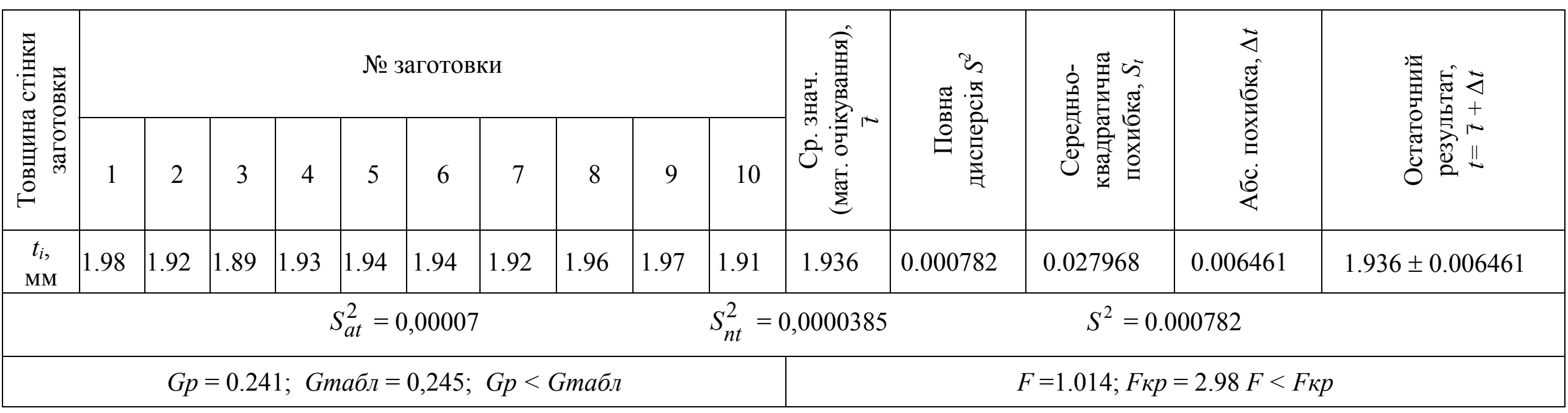

Статистична обробка вимірів товщини стінки заготовки з «Профіль армуючий зварний $50 \times 40$ мм» виконання ПГЗ

Таблиця 2

\begin{tabular}{|c|c|c|c|c|c|c|c|c|c|c|c|c|c|c|c|}
\hline \multirow{2}{*}{ 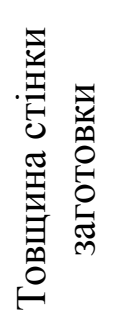 } & \multicolumn{10}{|c|}{ № заготовки } & \multirow{2}{*}{ 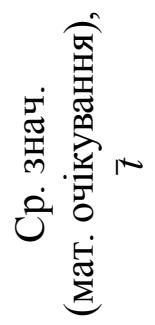 } & \multirow{2}{*}{ 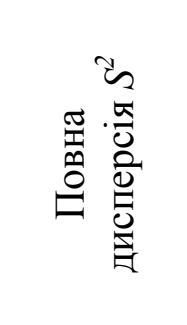 } & \multirow{2}{*}{ 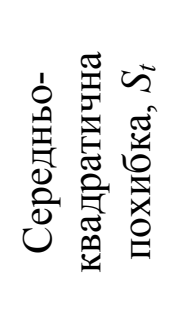 } & \multirow{2}{*}{ 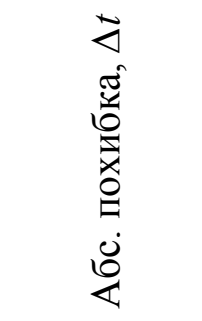 } & \multirow{2}{*}{ 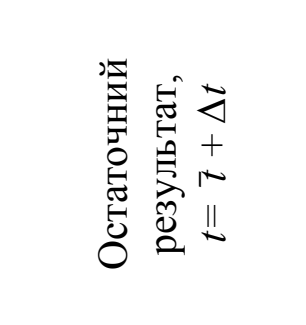 } \\
\hline & 1 & 2 & 3 & 4 & 5 & 6 & 7 & 8 & 9 & 10 & & & & & \\
\hline$t_{i}, \mathrm{MM}$ & 1.87 & 1.84 & 1.81 & 1.86 & 1.88 & 1.82 & 1.85 & 1.84 & 1.81 & 1.85 & 1.843 & 0.000579 & 0.02406 & 0.005558 & $1.843 \pm 0.005558$ \\
\hline \multicolumn{12}{|c|}{$S_{a t}^{2}=0,00005$} & \multicolumn{3}{|c|}{$S^{2}=0.000579$} & \\
\hline \multicolumn{11}{|c|}{$G p=0.157914 ;$ Gтабл $=0,245 ; G p<$ Gтабл } & \multicolumn{5}{|c|}{$F=1.551473 ; F_{\kappa} p=2.98 F<F_{\kappa} p$} \\
\hline
\end{tabular}




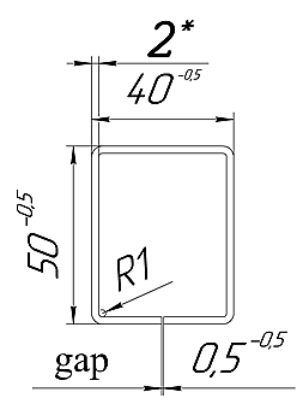

Рис. 1. Профіль армуючий гнутий (ПГ) типорозміру № $50 \times 40$

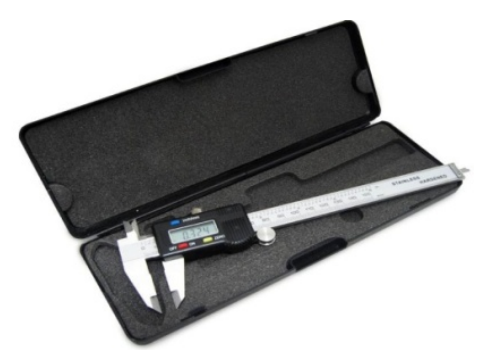

Рис. 3. Електронний штангенциркуль «Digital caliper A46»

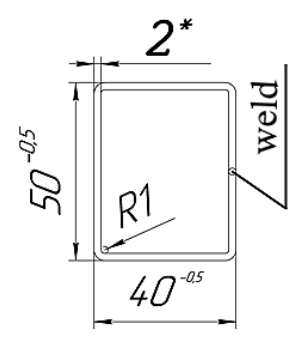

Рис. 2. Профіль армуючий гнутозварний (ПГЗ) типорозміру № $50 \times 40$

Основним визначальним параметром, що характеризує жорсткість і міцність профілю $\epsilon$ прогин профілю при згинанні поперечною силою. Для випробувань був обраний метод поперечного (три точкового) вигину (рис. 4). Даний метод підходить для контрольних і порівняльних випробувань.

За принципом, зазначеним на рис. 4, було розроблено методику випробувань із застосуванням експериментальної установки, що наведена на рис. 5. В якості випробувальної машини, що забезпечує навантаження профілю поперечною силою через циліндричну підставку діаметром 5,9 мм, використовували розривну машину УММ-10 з найбільшим граничним навантаженням 100 кН (рис. 6). В якості приладу, що фіксує прогин профілю, обраний механічний тензометр годинного типу від зразкового переносного динамометра ДОСМ-33 (рис. 7). Для фіксування даних показників сили $P$ використовували вбудовану в УММ-10 шкалу, зміна показань на якій протягом усього експерименту фіксувала камера, встановлена навпроти.

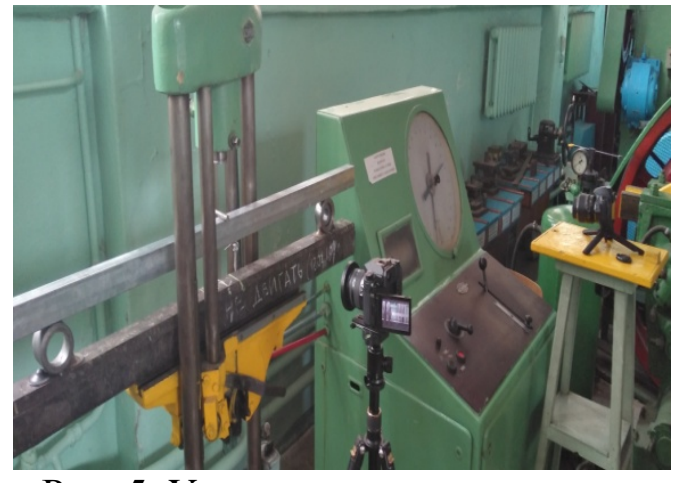

Рис. 5. Установка для проведення експериментального дослідження

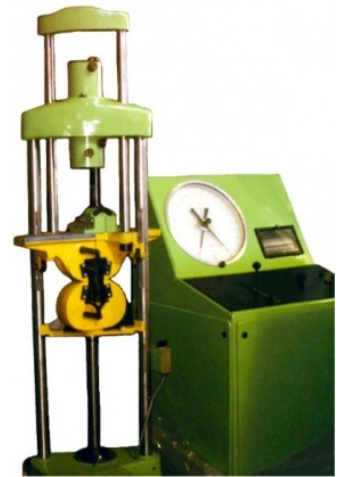

Рис. 6. Розривна машина УММ-10

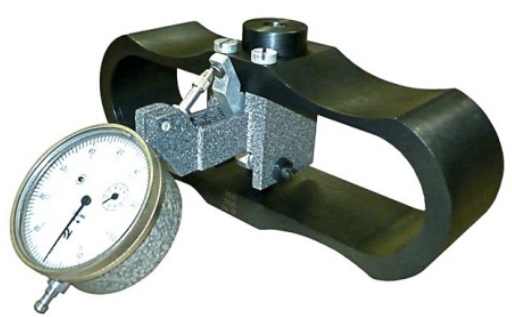

Рис. 7. Динамометр зразковий переносний ДОСМ-33

Таку ж схему використовували для спостереження за прогином профілю $f$, фіксуючи дані тензометра динамометра ДОСМ-33 за допомогою другої камери. Для фіксування даних показників приладів використовували камери високої роздільної здатності (Panasonic - G7, Panasonic - FZ300). Було проведено по три вимірювання із повною фіксацією подій для кожного виду і перерізу профілю (навантаженням на шов, на стик і на бічні грані). 
Для обробки результатів експерименту по визначенню сили і прогину профілів при навантаженні поперечною силою було використано допоміжне програмне забезпечення (ПЗ) DaVinci Resolve 15 i Microsoft Excel. ПЗ DaVinci Resolve 15 використовували для синхронізації обох камер. Отримані дані з відео дали можливість зіставити синхронізовані зміни значення сили $P$ і прогину профілю $f$ з плином часу, за якими були побудовані графічні залежності, наведені на рис. 8 і рис. 9.

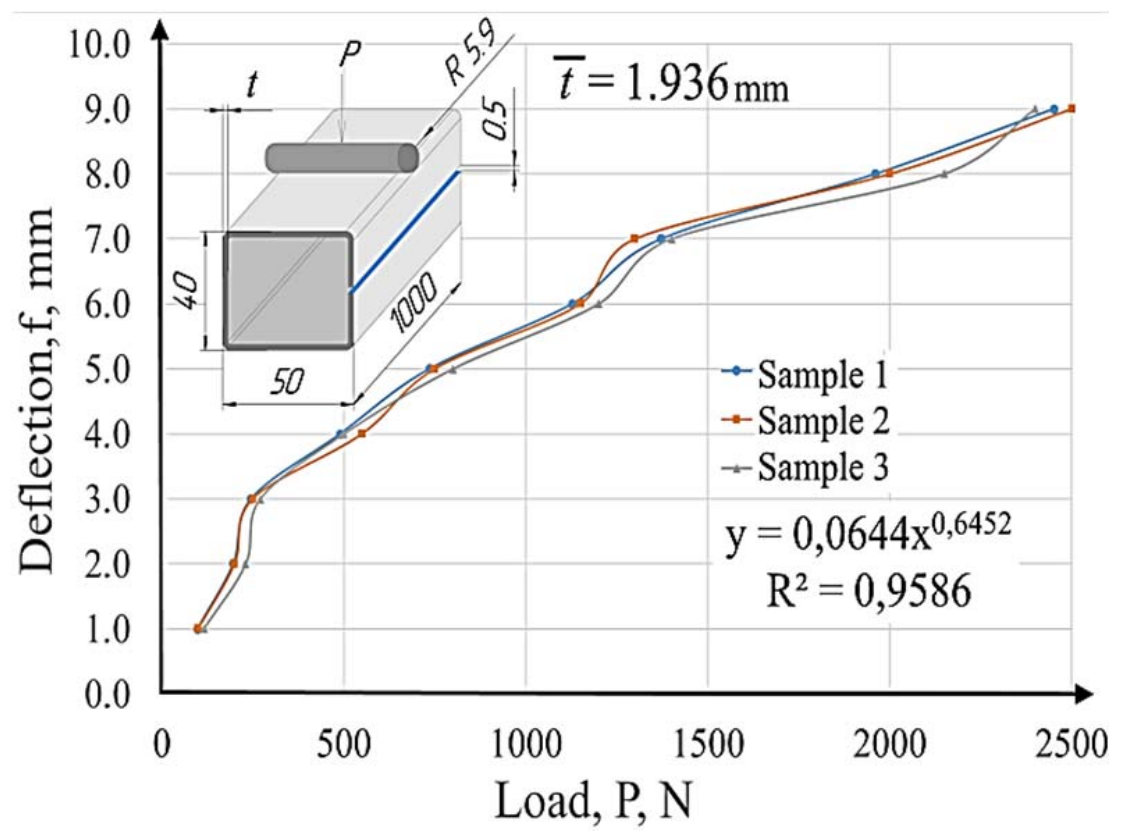

a

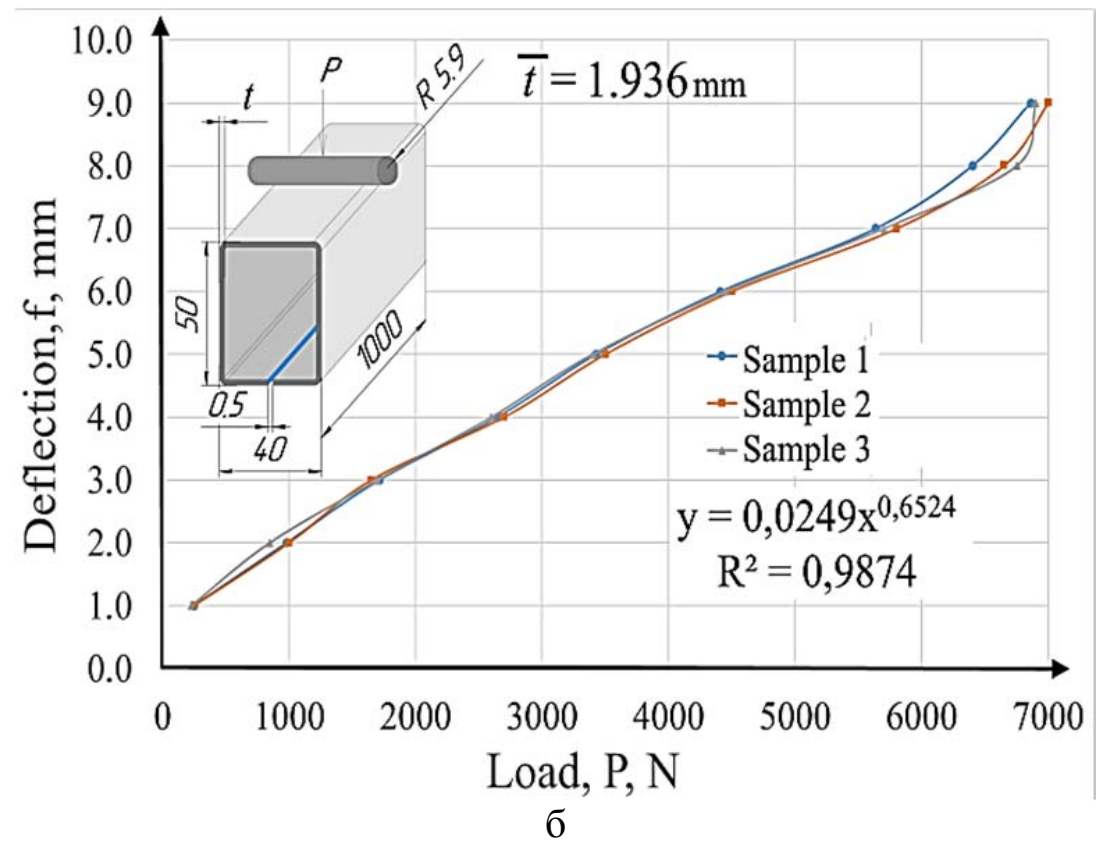

Рис. 8. Експериментальний графік результатів випробувань на поперечний прогин зосередженої силою профілів типорозміру № $40 \times 50(t=1,936$ мм) гнутого виконання (ПГ):

$\mathrm{a}$ - прикладення сили $P(50)$ до більшої сторони профілю; б - прикладення сили $P(40)$ до меншої сторони профілю

Після обробки отриманих графічних залежностей прогину від сили навантаження були отримані рівняння регресії (лінії тренду). Встановлено, що найбільш коректно функціональну залежність прогину від величини навантаження описують статечні рівняння з коефіцієнтом детермінації $\left(\mathrm{R}^{2}>0,95\right)$ : 
- для профілю ПГ:

$$
\begin{aligned}
& f=0,0644 \cdot P(50)^{0,6452} ; \\
& f=0,0249 \cdot P(40)^{0,6524},
\end{aligned}
$$

- для профілю ПГЗ:

$$
\begin{aligned}
& f=0,0151 \cdot P(50)^{0,7465} ; \\
& f=0,0275 \cdot P(40)^{0,6355} .
\end{aligned}
$$

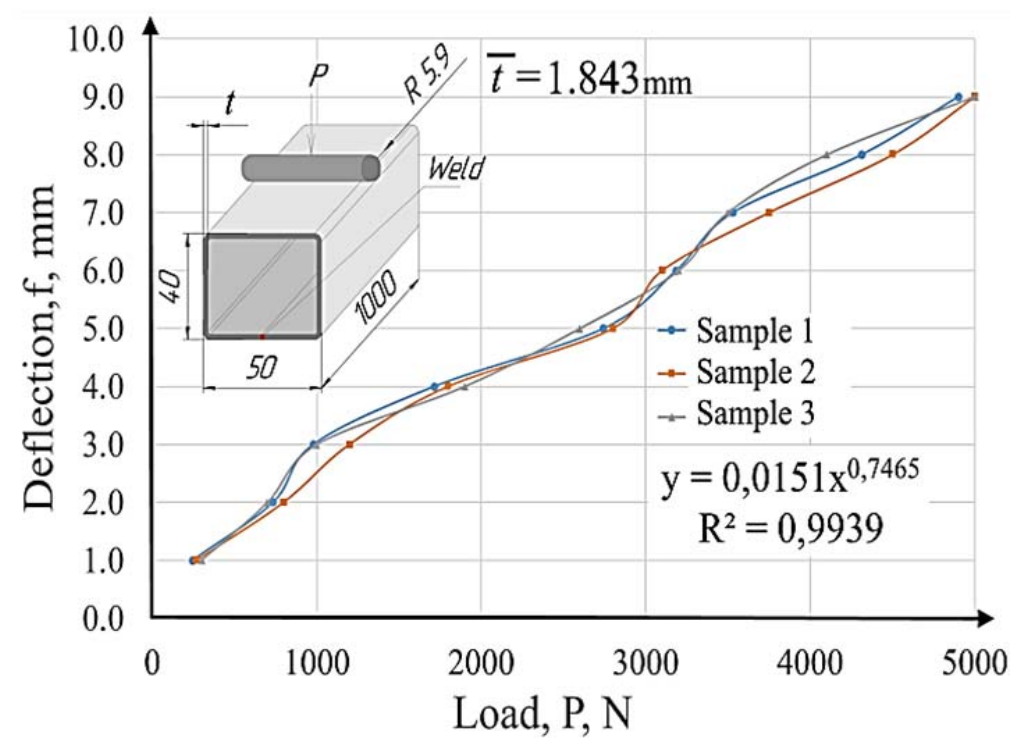

a



6

Рис. 9. Експериментальний графік результатів випробувань на поперечний прогин зосередженої силою профілів типорозміру № $40 \times 50 \quad(\mathrm{t}=1,843 \mathrm{mM})$ гнуто-зварного виконання (ПГЗ):

$\mathrm{a}$ - прикладення сили $\mathrm{P}(50)$ до більшої сторони профілю; б - прикладення сили $\mathrm{P}(40)$ до меншої сторони профілю 
Використовуючи вирази (1) - (4) можна охарактеризувати жорсткість армуючих профілів, задавшись фіксованою величиною сили - $500 \mathrm{H}$. В результаті розрахунку отримано величини прогинів $f$, відповідні навантаженню профілю, розміщеного на двох опорах, розташованих на відстані 1 м один від одного, поперечною силою, яка додається посередині довжини. Результати розрахунків наведені в табл. 3.

Таблиця 3

Величини прогинів $f$ холодногнутих армуючих профілів при навантаженні фіксованою вагою $P=500 \mathrm{H}$, і величини сил $P$, необхідних для їх деформації на фіксовану величину прогину $f=1,5$ мм

\begin{tabular}{|l|c|c|c|}
\hline $\begin{array}{c}\text { Виконання } \\
\text { профілю, } \\
\text { товщина стінки } \\
t, \text { мм }\end{array}$ & $\begin{array}{c}\text { Варіант прикладення } \\
\text { навантаження при } \\
\text { випробуванні }\end{array}$ & $\begin{array}{c}\text { Прогин, } f, \text { мм, } \\
\text { при навантаженні } \\
P=500 \mathrm{H}\end{array}$ & $\begin{array}{c}\text { Сила } P, \mathrm{H}, \\
\text { при прогині } \\
\text { профілю } \\
\text { на } f=1,5 \text { мм }\end{array}$ \\
\hline $\begin{array}{l}\text { ПГ } \\
t=1,936 \mathrm{mм}\end{array}$ & На більшу сторону $P(50)$ & 3,55 & 132 \\
\hline ПГЗ & На меншу сторону $P(40)$ & 1,44 & 534 \\
$t=1,843$ мм & На більшу сторону $P(50)$ & 1,56 & 474 \\
\cline { 2 - 4 } & На меншу сторону $P(40)$ & 1,43 & 540 \\
\hline
\end{tabular}

Таким чином, гнуто-зварний профіль ПГЗ показує кращі характеристики жорсткості, ніж гнутий ПГ, не дивлячись на більш тонку величину стінки (товщина стінки профілю ПГЗ на 4,8 \% менше, ніж профілю ПГ). Найгірші показники жорсткості має профіль гнутий ПГ при навантаженні на більшу сторону.

\section{ВИСНОВКИ}

Удосконалено методику експериментальних досліджень холодногнутих профілів на поперечний вигин прикладеною силою з безперервним відеозаписом процесу випробувань на фотокамери для отримання залежності між величиною навантаження і прогином профілю. Попередньо виконана статистична обробка результатів вимірювань товщини стінок, поставлених для випробувань армуючих профілів. Виявлено, що середні величини товщини стінок гнутого профілю ПГ на 4,8\% більше, ніж у профілів ПГЗ гнуто-зварного виконання, а відхилення товщини від середнього значення відповідають закону нормального розподілу.

Отримано графічні та аналітичні залежності величини прогину профілю при варіантах навантаження на велику стінку і на меншу стінку від величини навантаження. 3 аналізу графічних залежностей виявлено, що незважаючи на меншу на 4,8 \% товщину армуючого профілю ПГЗ в порівнянні з профілем ПГ, величина прогину для найбільш несприятливого випадку навантаження (на більшу сторону) зменшується на 59 \%, при навантаженні на меншу сторону прогин знижується на 0,7 \%.

Таким чином, наявність зварного шва підсилює характеристики жорсткості профілю. Виконання профілів в гнуто-звареному виконанні дозволить досягти необхідних параметрів жорсткості профілю при зменшенні товщини вихідної заготовки (штрипса), тобто економії металу заготовки. Встановлено, що виготовлення армуючих профілів у гнуто-зварному виконанні має переваги за показниками жорсткості перед профілями, що виготовлені у гнутому виконанні. Для найбільш несприятливого варіанту навантаження профілю на більшу сторону, коли незаварений зазор знаходиться на його бічній стороні, варіант формування зварного шву надасть покращення показника жорсткості не менш як на 50\%.

\section{СПИСОК ВИКОРИСТНОЇ ЛІТЕРАТУРИ}

1. Кухар В. В., Аніщенко О. С., Нагнібеда М. М. Методика розрахунку напружено-деформованого стану листової заготовки при гнутті з врахуванням зміцнення матеріалу. Вісник НТУ «ХПІ». Серія: Інноваційні технологї та обладнання обробки матеріалів у машинобудуванні та металургї. 2017. № 37(1259). С. 36-41. 
2. Кухарь В. В., Нагнибеда Н. Н. Испытание армирующих профилей и определение их прочностных и геометрических характеристик. Проблемы трибологии-Problems of tribology. Хмельницький. 2016. № 1(79). С. 30-35.

3. Rejzner J., Lexcellent C., Raniecki B. Pseudoelastic behaviour of shape memory alloy beams under pure bending: experiments and modelling. International Journal of Mechanical Sciences. 2002. № 44, pp. 665-686.

4. Bilston D., Ruan D., Candido A., Durandet Y. Parametric study of the cross-section shape of aluminium tubes in dynamic three-point bending. Thin-Walled Structures. 2019. № 136. pp. 315-322.

5. Nelson T., Bruton J., Rieske N.,Walton M., Fullwood D., Howel L. Material selection shape factors for compliant arrays in bending. Materials \& Design. 2016. № 110, pp. 865-877.

6. Sun Y., He A., Liang Y., Zhao O. In-plane bending behaviour and capacities of S690 high strength steel welded I-section beams. Journal of Constructional Steel Research. 2019. № 162. P. 105741.

7. Ahola A., Björk T., Barsoum Z. Fatigue strength capacity of load-carrying fillet welds on ultra-high-strength steel plates subjected to out-of-plane bending. Engineering Structures. 2019. № 196. P. 109282.

8. Dang X., He K., Zhang F., Zuo Q., Du R. Multi-stage incremental bending to form doubly curved metal plates based on bending limit diagram. International Journal of Mechanical Sciences. 2019. № 159. P. 1930.

9. ДСТУ ГОСТ 8.207:2008. Прямые измерения с многократными наблюдениями. Методы обработки результатов наблюдений. Основные положения. Київ: Держспоживстандарт Українию, 2008. 8 с.

10. Гмурман В. Е. Теория вероятности и математическая статистика. Москва : Высшая школа, 1972. 368 с.

11. Гаскаров Д. В., Шаповалов В. И. Малая выборка. Москва : Статистика, 1978. 248 с.

\section{REFERENCES}

1. Kukhar V.V., Anishchenko O.S., Nagnibeda M.M., Method of calculation of stress-strain state of sheet billet in bending taking into account material strengthening. Bulletin of NTU "KhPI". 2017, 37 (1259), pp. 36-41. (in Ukrainian).

2. Kuhar V.V., Nagnibeda N.N. Testing of reinforcing profiles and determination of their strength and geometric characteristics. Problems of tribology. Khmelnitsky: KhNU. 2016, 1 (79), pp. 30-35. (in Russian).

3. Rejzner J., Lexcellent C., Raniecki B. Pseudoelastic behaviour of shape memory alloy beams under pure bending: experiments and modelling. International Journal of Mechanical Sciences. 2002, 44, pp. 665-686.

4. Bilston D., Ruan D., Candido A., Durandet Y. Parametric study of the cross-section shape of aluminium tubes in dynamic three-point bending. Thin-Walled Structures. 2019, 136, pp. 315-322.

5. Nelson T., Bruton J., Rieske N., Walton M., Fullwood D., Howel L. Material selection shape factors for compliant arrays in bending. Materials \& Design. 2016, 110, pp. 865-877.

6. Sun Y., He A., Liang Y., Zhao O. In-plane bending behaviour and capacities of S690 high strength steel welded I-section beams. Journal of Constructional Steel Research. 2019, 162, p. 105741.

7. Ahola A, Björk T., Barsoum Z. Fatigue strength capacity of load-carrying fillet welds on ultra-high-strength steel plates subjected to out-of-plane bending. Engineering Structures. 2019, 169, p. 109282.

8. Dang X., He K., Zhang F., Zuo Q., Du R. Multi-stage incremental bending to form doubly curved metal plates based on bending limit diagram. International Journal of Mechanical Sciences. 2019, 159, p.1930.

9. DSTU GOST 8.207: 2008. Direct measurements with multiple observations. Methods of processing the results of observations. Kyiv: Statestandart. 2008. (in Russian).

10. Gmurman V.E. Probability theory and mathematical statistics. Moscow: Higher School. 1972, 368 p. (in Russian).

11. Gaskarov D.V., Shapovalov V.I. Small sample. Moscow: Statistics. 1978, 248 p. (in Russian).

Нагнібеда М. М. - аспірант ПДТУ;

Кухар В. В. $\quad$ - д-р техн. наук, проф., зав. каф. ПДТУ;

E-mail: fox7941@gmail.com; kvv.mariupol@gmail.com

Ткачов Р. О. - - зав. лаб. ПДТУ;

Радушев О. О. - інж. ПДТУ;

Ясько С. Г. $\quad$ - ст. викл. НУ «Полтавська політехніка ім. Ю. Кондратюка»;

Фролов Є. А. - - д-р техн. наук, проф. НУ «Полтавська політехніка

ім. Ю. Кондратюка».

ПДТУ - Приазовський державній технічний університет, м. Маріуполь.

НУ «Полтавська політехніка ім. Ю. Кондратюка»- Національний університет «Полтавська політехніка імені Юрія Кондратюка», м. Полтава. 